\title{
LA INMIGRACIÓN MORISCA EN TÚNEZ. SU INFLUENCIA EN EL ÁMBITO ECONÓMICO-CULTURAL Y EN LA CONFORMACIÓN DE LA MODERNA NACIONALIDAD TUNECINA
}

Juan B. Vilar*

\section{NOTA PRELIMINAR}

Mi aportación es una síntesis reelaborada y actualizada de diferentes estudios que he realizado en los últimos veinte años sobre el exilio morisco-andalusí en Túnez, y la contribución de este colectivo al proceso modernizador de ese país y a la conformación de la actual nacionalidad tunecina. Entre esas aportaciones deseo mencionar expresamente dos libros aparecidos en 1991 y 1992 sobre la cartografía hispánica de Túnez ${ }^{1}$ y sobre el éxodo morisco ${ }^{2}$, publicados respectivamente por la Agencia Española de Cooperación Internacional y por la murciana Real Academia "Alfonso X el Sabio", y prologados ambos por nuestro recordado amigo, colega y maestro el Dr. Míkel de Epalza Ferrer, a quien tributamos con el presente Congreso un muy merecido homenaje.

\section{LOS FLUJOS MIGRATORIOS MORISCOS HACIA TÚNEZ ANTES Y DESPUÉS DEL DECRETO DE EXPULSIÓN}

La expulsión de los moriscos entre 1609 y 1614, acaso el acontecimiento más trascendente de la historia española en el siglo XVII, tuvo inmediata repercusión

\footnotetext{
* Universidad de Murcia.

1. J.B. VILAR, Mapas, planos y fortificaciones hispánicos de Túnez (s. XVI-XIX) / Cartes, plans et fortifications hispaniques de la Tunisie (XVI $I$-XIX ${ }^{e}$. s.), prólogo de M. de Epalza, Madrid, 1991 (en especial cap. V y ss.: "Mapas sectoriales de Túnez", pp. 314-467).

2. J.B. VILAR, «Murcia y el Levante peninsular en la inmigración morisca en Túnez», en J.B. VILAR, Los moriscos del Reino de Murcia y Obispado de Orihuela, prólogo de M. de Epalza, Murcia. 1992, pp. 193-229.
} 
en la Regencia turca de Túnez, convertida en uno de los principales países de destino. No podía ser de otra forma, y no sólo por razones de proximidad geográfica y por las circunstancias singularmente propicias que se dieron en esta ocasión, a las que después he de referirme, sino también por la reputación bien fundada de que gozaba Túnez entre los musulmanes españoles como país tolerante y acogedor, reputación acreditada por una tradición multisecular de ser el refugio preferido por los inmigrados de Al-Andalus. Como refiere Luis F. Bernabé Pons", Túnez representaba para ellos "la nación [morisca] en lugar seguro".

Esa opinión mantendrá toda su vigencia para el siglo XVI en relación con la Tunicia hafsí, fomentada por cuantos moriscos, de regreso del preceptivo viaje a La Meca, establecían comparaciones entre los diferentes países visitados. Sobre el particular no se sabe demasiado, dado el carácter esotérico de tales viajes, al menos contemplados desde España, pero no faltan testimonios ${ }^{4}$.

Con anterioridad a la expulsión, Túnez emerge ya como uno de los dos o tres principales puntos de recepción del espontáneo drenaje de moriscos dirigido al norte de África. Para Louis Cardaillac ${ }^{5}$ esta emigración se canalizaba por tres rutas clandestinas principales: la que pasando por Aragón, el Pirineo y el SE francés, se prolongaba por vía marítima hasta Túnez; la ruta CartagenaArgel, y la de Andalucía-Marruecos. La primera de esas rutas es acaso la mejor documentada ${ }^{6}$, por más que deba subrayarse que no era la única que conducía al antiguo reino hafsida, dado que los moriscos marchaban también directamente allí, sobre todo desde el litoral valenciano, Murcia y Baleares, por no hablar de quienes lo hacían vía Italia o rebotados desde territorios magrebíes que les eran menos propicios, la Regencia de Argel en primer lugar.

Epalza alude al goteo de moriscos que precedió a la emigración masiva de 1609-1614. En cuanto a la ruta franco-aragonesa afirma que en el momento de la expulsión “... ya algunos emigrantes estaban instalados en el sur de Francia y colaboraron en el tránsito de los expulsados aragoneses, como el Dr. Calatrava, de Almonacid de la Sierra, instalado en Marsella" ${ }^{\prime 7}$. Los itinerarios se-

3. L.F. BERNABÉ PONS, «La nación en lugar seguro: los moriscos hacia Túnez», en V. FANJUL MARLÉ (coord.), Cartas de la Goleta. Actas del Coloquio Internacional "Los moriscos y Túnez" (noviembre, 2008), Túnez, 2009, pp. 107-118.

4. Véase por ejemplo M. de EPALZA, «Deux récits bilingues (arabe et espagnol) de voyageurs vers l'Orient qui passent par Tunis $\left(\mathrm{XV}^{\mathrm{e}}\right.$ et $\mathrm{XVI}^{\mathrm{e}}$ siècles)», Les Cahiers de Tunisie, XXVI, 103 104, 1978, pp. 35-52.

5. L. CARDaillac, Moriscos y cristianos. Un enfrentamiento polémico (1492-1640), prefacio de F. Braudel, Madrid, 1979, p. 79 (hay múltiples ediciones de la versión original francesa, y traducción al árabe de A. Temimi, Tunis, 1983 -2ª ed., Zaghouan, 1989-). Vid. también H. Ch. LEA, Los moriscos españoles. Su conversión y expulsión, estudio preliminar y notas de R. Benítez Sánchez-Blanco, trad. de J. Lorenzo Miralles, Alicante, 2001, pp. 341-440.

6. AHN, Inquisición, legs. 193, nº 10; 196, n 19 (citados por L. CARDAILLAC, op. cit.).

7. M. de EpAlZA, «El escritor Ibrahim Taybili y los escritores musulmanes aragoneses», introducción a L.F. BERNABÉ PONS, El cántico islámico del morisco hispanotunecino Taybili, Zaragoza, 1988 , p. 7. 
guidos por los emigrados en el SE francés han sido investigados, entre otros, por L. Cardaillac, L. López-Baralt y A. Irizarry, M. de Epalza, C. Ansón, J. Fournel-Guerin y H.E.J. Stanley ${ }^{8}$.

De la relevancia del objetivo tunecino en estas emigraciones furtivas baste decir que Carlos V estimó oportuno incluir la prohibición de las mismas, y la persecución de los inmigrados, en el tratado que en 1535 firmó son su protegido Mulay Hassan en el momento de restablecerle en el trono. Tampoco los moriscos peninsulares andaban ayunos de noticias sobre cuanto acontecía en el país magrebí, a la sazón estrechamente vinculado a España. Si Lepanto y la campaña de don Juan de Austria en Túnez les entristeció ${ }^{9}$, sucedió todo lo contrario al saberse de la pérdida por España de La Goleta en 1574, y de la definitiva expulsión de los cristianos españoles de aquellos parajes.

Refiere Cardaillac al respecto ${ }^{10}$ que en los más recónditos pueblos de Aragón y Castilla los moriscos comentaban el acontecimiento, y en tanto ellos seguían con avidez estas noticias, los otros habitantes, los cristianos viejos, se mostraban bastante indiferentes por tan lejanos sucesos. Cardaillac, siguiendo un proceso inquisitorial, trae a colación un caso, el del pueblo aragonés de Cariñena, donde así como en sus alrededores, “... los moriscos hazían regozijos y estaban alegres; [el declarante] le preguntó al dicho morisco: ¿Vosotros qué tenéis que estáis tan alegres?; el dicho morisco le dixo que porque el turco a tomado una fortaleza, y no se le acuerda el declarante qué nombre dixo, y diziéndole si dixo La Golera o Túnez o el Fuerte, dixo que no se acuerda"11.

Decretada la expulsión, un nutrido contingente de aragoneses, castellanos y algunos de la baja Cataluña tomaron el camino de Túnez por la vía francesa ya mencionada. Otros de igual procedencia lo hicieron desde Italia, en tanto que valencianos, murcianos, algunos andaluces y los de las Islas Baleares alcanzaban el litoral de Túnez desde los puertos argelinos donde habían desembarcado, desde Italia, Francia, diferentes dependencias de la Puerta, o directamente ${ }^{12}$.

El grupo aragonés parece haber sido el más numeroso en esta inmigración. Muy aculturados en cuanto a la lengua, dado que hablaban casi exclusivamen-

8. Citados por M. de EpALZA, «El escritor Ibrahim Taybili...». Vid. también Id., «Le milieu hispanomoresque de l'évangile islamisant de Barnabé (XVIe-XVIIe s.)», Islamochristiana, 8, 1982, pp. 166-167. Múltiples noticias a su vez en L.F. BERnABÉ PONS, El cántico islámico...

9. Sobre el impacto de la episódica ocupación española de Túnez en el XVII, vid. J.B. VILAR, «La ocupación de Túnez por España en 1573 y la fundación de la ciudadela de Nova Arx a través de dos cartas de Don Juan de Austria a Guzmán de Silva, embajador español en Venecia», en A. Temimi (ed.), Melanges Louis Cardaillac, Zaghouan, 1995, t. II, pp. 721-734.

10. L. Cardaillac, op. cit., p. 81.

11. Cfr. Ibídem, pp. 81-82.

12. Véase estado de la cuestión sobre el tema, con resumen y análisis crítico de aportaciones precedentes en A. Domínguez OrTIZ y B. VINCENT, Historia de los moriscos, vida y tragedia de una minoría, Madrid, 1978 (especialmente cap. 11: "La diáspora morisca", pp. 225-245). 
te castellano, con ellos tiene que ver la mayor parte de los manuscritos de controversia religiosa, escritos en la lengua de Cervantes con caracteres aljamiados -en ocasiones incluso latinos- conservados en su mayoría en las bibliotecas de España e Italia, y que han sido recopilados, entre otros, por E. Saavedra ${ }^{13}$, F. Guillén Robles $^{14}$, J. Ribera -con M. Asín Palacios_ ${ }^{15}$, L.P. Harvey ${ }^{16}$ o A. Vespertino Rodríguez $^{17}$, y estudiados a partir de los ya mencionados por A. González Palencia, P. Gil, C. López Morillas, L. Cardaillac, M. de Epalza, M. Fierro, M. García-Arenal, A. Labarta, etc., dado que afortunadamente son legión.

Se conocen relativamente bien las manifestaciones literarias en lengua castellana de los moriscos expulsos y de sus descendientes inmediatos, pero bastante menos la literatura en árabe de esos exiliados, sobre la cual contamos con aportaciones puntuales como las de M. de Epalza (con R. Petit) ${ }^{18}$, L.F. Bernabé Pons ${ }^{19}$, L. López-Baralt ${ }^{20}$, A. Vespertino Rodríguez ${ }^{21}$, o A. Gafsi-Slama ${ }^{22}$, quienes nos remiten a los textos conservados, de interés histórico-documental sobre todo (cartas, testimonios, inscripciones funerarias y ornamentales, etc.), pero también propiamente literarios, como los conocidos malouf o cantos y poemas musicales, y los de contenido religioso (los más numerosos), unos y otros de neta raigambre andalusí o evocadores de la patria perdida.

Todo ello nos lleva a la debatida cuestión del grado de arabización de la población morisca en el momento de la expulsión. El conocimiento de la lengua árabe era sin duda signo de afirmación de la identidad de esa minoría española, aunque no tanto como la religión islámica, dado que tal conocimiento era minoritario, y con frecuencia superficial, en una población en avanzado proceso de castellanización, y en determinadas áreas del frente oriental de la Península, de catalanización, a juzgar por los testimonios conservados ${ }^{23}$.

13. E. SAAVEDRA, Índice general de la literatura aljamiada, Madrid, 1878 y 1889.

14. F. Guillén Robles, Catálogo de los manuscritos árabes existentes en la Biblioteca Nacional de Madrid, Madrid, 1889.

15. J. Ribera y M. Asín [Palacios], Manuscritos árabes y aljamiados de la Biblioteca de la Junta, Madrid, 1912.

16. L.P. HARVEY, The Literary Culture of the Moriscos, Oxford, 1958.

17. A. Vespertino RodrígueZ, «Una aproximación a la datación de los manuscritos aljamiadomoriscos», Estudios Románicos, 5, 1989, II, pp. 1420-1439 (Homenaje al Prof. L. Rubio).

18. M. de Epalza y R. Petrt (eds.), Recueil d'Etudes sur les Moriscos andalous en Tunisie, Madrid, 1973.

19. L.F. BERNABÉ PONS, Bibliografía de la literatura aljamiado-morisca, Alicante, 1992.

20. L. López-BARALt, Un Kâma Sûtra español, Madrid, 1992.

21. A. Vespertino RodrígueZ, «La literatura aljamiado-morisca del exilio», en M. de Epalza (ed.), L'expulsió dels moriscos. Conseqüiències en el món islàmic i en el món christià, Barcelona, 1994, pp. 183-194.

22. A. GAFSI-SLAmA, «Aproximación al estudio de los textos en árabe de los morisco-andalusíes en Tunicia», Sharq Al-Andalus, 12, 1995, pp. 413-429.

23. Vid. B. VincENT, «La langue des morisques», Actas del III Simposio Internacional de Estudios Moriscos. Las Prácticas Musulmanas de los Moriscos Andaluces (1492-1609), Zaghouan (Túnez), 1989, pp. 
En tanto la inmigración morisca era asimilada con relativa celeridad por los países islámicos de recepción desde Marruecos a Turquía, Túnez constituye un caso particular. Aquí la colectividad criptomusulmana llegada de España mantuvo su personalidad y peculiaridades tanto en razón de la cuantía de sus efectivos y la concentración de que fue objeto en una región de extensión limitada, como por las peculiares circunstancias que se dieron en el asentamiento de la misma.

De un lado en la capital de la Regencia la inserción de los recién llegados se vio favorecida por la decidida protección que les prestó el influyente Sidi Abū al-Gayt, o Bulgayz, acaudalado árabe tunecino director y administrador de fundaciones piadosas, que les dedicó parte de los fondos benéficos por él controlados, reunió a los inmigrados en instituciones expresamente creadas para ellos, les protegió contra reacciones xenófobas, e hizo que determinadas familias acogieran otra morisca. Aunque les permitió que mantuvieran su personalidad cultural e incluso que completaran su instrucción islámica en castellano, sus directrices a medio plazo se revelaron eficazmente asimilacionistas ${ }^{24}$.

El otro y principal protector de los moriscos fue el gobernador turco Uțmān Dey, enérgico y eficiente gobernante que supo frenar el caos políticoadministrativo y las interminables reyertas a que se veía abocado el país desde las décadas iniciales del siglo XVI. Uțmān, a quien no se escapaba que en el fondo de esa inestabilidad y agitaciones se hallaba la realidad evidente de la imposición al país de una exigua minoría militar, la turca, aceptada por necesidad por la población árabo-bereber para conjurar una amenaza mayor, la dominación cristiana y española, imposición aquélla tanto más inestable y discutida conforme fueron variando las circunstancias históricas que aconsejaron inicialmente el protectorado otomano, vio en la llegada masiva de los moriscos la posibilidad de un mejor equilibrio en el panorama étnico-cultural tunecino en beneficio de la precaria dominación de la Sublime Puerta ${ }^{25}$.

181-188; Id., «Los moriscos y los idiomas árabe, castellano y catalán», en E. LORENZO SANZ (coord.), Proyección histórica de España en sus tres culturas: Castilla-León, África y el Mediterráneo, Valladolid, 1993, pp. 369-378; L. CARDAILLAC, op. cit. Uno y otro autor remiten a las fuentes y documentación disponibles.

24. M. de EPAlZA, «Sidi Bulgayz, protector de los moriscos exiliados en Túnez (s. XVII). Nuevos documentos traducidos y estudiados», Sharq Al-Andalus, 16-17, 1999-2000, pp. 145-176. Vid. también A. TEMINI, Le Gouvernement ottoman et le probleme morisque, Zaghouan, 1989. Vid. a su vez M. RAZÛQ, «Les inmigrés andalous au Maghreb (Tunisie et Algèrie)», Revue d'Histoire Maghrébine, 43-44, 1986, pp. 146-199; N. ZBISS, «La Tunisie, terre d'accueil des morisques venus d'Espagne au début XVII'. siécle», Actes du IV . CIEM, Túnez, 1990, pp. 337-342.

25. Véanse, entre otros, J. Penella Roma, Los moriscos españoles emigrados al norte de África después de la expulsión de 1609, Barcelona, 1970, 3 vols. (multicopista) -tres capítulos publicados en francés en M. de EPAlza y R. PETIT, op. cit.-; H. PIERI, «L'accueil par des tunisiens aux morisques expulsés d'Espagne: un témoignage morisque», Ibla, XII, 118, 1968, pp. 63-70; J.D. LATHAM, «Towards a study of Andalusian history», Les Cahiers de Tunisie, 19-20, 1957, pp. 203-252; Id., «Contribution à l'étude de l'inmigration andalouise et leur place dans l'histoire de la Tunisie», en M. de Epalza y R. PetIT, op. cit., pp. 21-63; A. TURKI, «Documents sur le dernier exode des Andalous en Tunisie», en M. de EPAlZA y R. PetrT, op. cit., pp. 114-127; A.J. HeSS, «The Moriscos: an Ottoman fifth column in sixteenth-century Spain», The American Historical Review, 84, 
A tal fin, después de haber pacificado el país, con gran visión política creó una nueva comunidad, la andalusí, con personalidad y estatuto jurídico propios, a la que instaló en puntos concretos en condiciones harto favorables, y que por su carácter moderno y expansivo -introdujo técnicas artesanales y agronómicas bastante más avanzadas que las usuales en el país- estaba llamada a convertirse en sólido punto de apoyo de sus protectores otomanos. El resultado fue, como refiere Míkel de Epalza ${ }^{26}$, "...la creación de un auténtico grupo étnico, coherente e inasimilable, al menos en los primeros tiempos", o en frase de un escritor morisco tunecino "sus genízaros sin sueldo" ${ }^{27}$. Tal política protectora sería ratificada y reforzada mediante un firmán del sultán otomano de 6 de julio de 1615, que reconocía a los moriscos inmigrados en el deyato tunecino (mudayyal o "mudéjares" se les llama en el texto turco) rango de minoría con entidad propia, en igualdad de condiciones con las otras minorías nacionales en que se apoyaba la Sublime Puerta para controlar y administrar sus vastos dominios ${ }^{28}$.

\section{LOS FUNDAMENTOS ISLÁMICO-CULTURALES DEL COLECTIVO INMIGRADO}

Tanto o más que la integración en el país, urgía a los moriscos recuperar por entero sus raíces religiosas y culturales. Aún los sinceros musulmanes no dejaban de tener arraigadas, en diversa medida, creencias y prácticas cristianas en las que habían vivido, siquiera externamente, desde su nacimiento. El morisco refugiado en Túnez, Juan Alonso Aragonés, musulmán observantísimo, alertará por ello a sus compañeros de exilio, exhortándoles a desterrar de su espíritu toda huella de cristianismo, bajo pena de condenación eterna ${ }^{29}$.

Prevenciones que sin duda no eran ociosas, por más que la mayoría de sus correligionarios en Túnez fueran sinceros musulmanes, como lo subraya

1968, pp. 1-25; A. TEMIMI, «Le Gouvernement ottoman face au probleme morisque», Revue d'Histoire Maghrébine, 23-24, 1981, pp. 249-262 (reimpreso en Les Morisques et leur temps, Table Ronde Internationale, Montpellier, juillet 1981, París, 1983, pp. 297-313). Sobre la inmigración morisca en Túnez y su inserción en la sociedad tunecina existe extensa bibliografía recogida en considerable medida en tres repertorios: M. de EPALZA, «Recherches récentes sur les emigrations des 'moriscos' de Tunisie», Les Cahiers de Tunisie, XVIII, 1970, pp. 139-147; Id., «Trabajos actuales sobre la comunidad de moriscos refugiados en Túnez, desde el siglo XVII a nuestros días», Actas del Coloquio Internacional sobre Literatura Aljamiada y Morisca (Oviedo, 1972), Madrid, 1978, pp. 427-442; R. PETIT, «Bibliographie generale», Recueil d'études sur les Moriscos andalous en Tunisie, Madrid, 1973, pp. 9-15.

26. M. de EPALZA, «Trabajos actuales sobre la comunidad de moriscos...», p. 430.

27. Texto de Ibn Abd al-Rafi, citado por J. Oliver Asín, «Un morisco de Túnez, admirador de Lope. Estudio del Ms. de la Colección Gayangos», Al-Andalus, 1, 1933, pp. 409-456.

28. Vid. A. Temimi, Études d'histoire morisque I Dirâsât fi al-târij al-mûrîskî al-andalusî, Zaghouan, 1993, pp. 77-90.

29. Vid. exhortación literal de Aragonés a sus correligionarios, en L. CARDAILLAC, op. cit., p. 91. 
Muhammad Alguacir, uno de ellos, a quien se refiere Mercedes García-Arenal $^{30}$, para quien no ya en la emigración, sino en la propia España, el morisco difícilmente traicionaba su ley no obstante acechanzas y persecuciones ${ }^{31}$. Sin embargo, por otras fuentes, en particular los manuscritos de controversia, consta que la aculturación entre algunos moriscos era tan intensa que no solamente habían abandonado la práctica de la fe islámica sino también olvidado su lengua y cultura ancestrales. Su reeducación en Túnez hubo de cubrir por tanto ambos frentes, empeño laborioso en el que, en ocasiones, se tuvo que partir de cero, escribiéndoles catecismos musulmanes en español. Como subrayaría uno de los catequistas ${ }^{32}$, ciertos catecúmenos “...no alcanzan la lengua arábiga ques la perfecta, y neçesitando de esta vulgar castellana ques en la que Dios permitió se criasen sin poder aprender la otra, a sido fuerça el haçerles este tratado".

Desde luego el grado de hispanización de los inmigrados resultaba más que estimable en el momento de su llegada a Túnez, al punto de generar en éste y otros países del Magreb un florecimiento literario que, para algunos estudiosos de esta minoría, es muy digno de figurar con entidad propia entre las corrientes específicas de nuestro Siglo de Oro. En efecto, para Julio Samsó, por ejemplo, “...los moriscos serán en Túnez (como en otros países del África del Norte) embajadores no ya de una cultura hispanoárabe ya muerta, sino de una cultura fundamentalmente española y renacentista, aunque en ella asome el sustrato andalusí" ${ }^{\prime 3}$. Sus literatos conocían bien los clásicos castellanos, incluidos los coetáneos de la expulsión. Así Ibrahim Taybili (antes Juan Pérez), afincado en Testour, autor de un poema de 5.000 versos en octavas reales y buen conocedor de Cervantes (el Quijote) y de los libros de caballerías (que denosta), sin perjuicio de dedicar al Profeta Muhammad varios poemas (en sonetos).

Bien es cierto que tan positiva opinión sobre el grado de hispanización de la elite intelectual morisca dista de ser unánime. Para Álvaro Galmés de Fuentes, por ejemplo, la integración de la minoría morisca en el contexto español ambiental no fue tan lejos como se ha pretendido, por cuanto tal percepción obedece a que la historiografía ha utilizado de forma preferente "testimonios desde la perspectiva cristiana, en particular documentos de la Inquisición, que ofrecen una visión partidista de los moriscos" ${ }^{\prime 34}$. A su juicio la realidad era otra.

30. M. García-Arenal y F. Rodríguez Mediano, Un Oriente español. Los moriscos y el Sacromonte en tiempos de Contrarreforma, Madrid, pp. 279-299.

31. Vid. L. CARDAILlaC, op. cit., p. 96. Sobre igual temática véase M. TURKI, «Les Andalous Morisques en Tunisie à la recherche d'un univers mythique et religieux personal», Actas del III Simposio Internacional de Estudios Moriscos. Las prácticas musulmanas de los Moriscos Andaluces (14921609), Zaghouan (Tunez), 1989, pp. 79-180.

32. Cfr. L. CARDAillac, op. cit., p. 171. Vid. también M. de EpalzA, «La vie intellectuelle en espagnol des morisques au Maghreb (XVII'. siécle)», Revue d'Histoire Maghrébine, 59-60, 1990, pp. 73-78.

33. J. SAMSÓ, «Los moriscos y la cultura norteafricana», Cuadernos. Historia 16, 97, 1997, p. 28.

34. A. GALMÉS DE FuENTES, «La conversión de los moriscos y su pretendida aculturación», en R. GIL GRIMAU (dir.), La política y los moriscos en la época de los Austrias. Actas del Encuentro (diciembre 1998), Madrid, 1999, p. 157. 
Conservaron la fe islámica como eje central de su entidad, y por extensión el apego a su lengua, cultura y tradiciones ancestrales en mucha mayor medida de lo que suele decirse. Hasta el punto de que no obstante evidentes concesiones a la lengua y cultura del entorno, e incluso a aportaciones reseñables como las estudiadas por Luis F. Bernabé Pons ${ }^{35}$, como refiere Rodolfo Gil ${ }^{36}$, "llegaron a ser extraños en su tierra".

Cuestiones como éstas, o las derivadas del lógico rechazo de los recién llegados por parte de vastos sectores de la población al sentirse perjudicados en sus intereses por la competencia de los inmigrantes, por no hablar de las privaciones inherentes a toda inmigración forzosa y al asentamiento en un país extraño, nos invita a intuir las penalidades sufridas por la diáspora morisca en Túnez, sobre las cuales no faltan testimonios $\operatorname{concretos}^{37}$. Aun cuando aquí la acogida resultó por lo general más bonancible que en la mayor parte de los puntos de recepción situados en Argelia y Marruecos, no por ello dejó de conllevar toda suerte de tribulaciones y angustias físicas, y sobre todo morales, inherentes a todo exilio.

Ahora bien, no faltan autores reseñables que relativizan el exilio como tragedia tanto personal como colectiva, e incluso el alcance traumático de la precedente expulsión. Entre ellos L. Cardaillac, quien de entrada rebaja la carga negativa de ésta al situarla en el contexto europeo del momento, en que por doquier se estaba produciendo la perfilación y reafirmación de estados nacionales con un sentido reduccionista: prescindir de las minorías; en España de las minorías religiosas, o por mejor decir, religioso-culturales. Esfuerzo asimilista que se remonta en Castilla al bajo Medievo, y se acentuará a partir de la unificación española con los Reyes Católicos, culminando a comienzos del siglo XVII con la expulsión de los últimos refractarios: el colectivo morisco no asimilado ${ }^{38}$.

En cualquier caso conviene también Cardaillac en que la forzada asimilación de esa como de las demás minorías conllevaría la negación de su identidad, y llegado el caso (como sucedió con los moriscos) se recurrirá a la represión, a la deportación e incluso a la eliminación física de los diferentes. Técnicas asimilistas que en mayor o menor medida el exiliado hubo de sufrir también en Tunicia y en los otros países de destino.

35. L.F. Bernabé Pons, El texto morisco del Evangelio de San Bernabé, Granada, 1998, pp. 37-42; Id., El cántico islámico del morisco hispano-tunecino Taybili, Zaragoza, 1988; Id., "L'ecrivain morisque hispano-tunisien Ibrahim Taybili», en M.H. FANTAR y S. KHADDAR-ZANGAR (coords.), Mélanges d'Archéologie, d'Epigraphie et d'Histoire offerts à Slimane Mustapha Zbiss, Tunis, 2001, pp. 247-272.

36. «La marginalidad de los moriscos, un fenómeno impuesto», en M.H. FANTAR y S. KHADDARZANGAR (coords.), op. cit., p. 175.

37. L. LÓPEZ-BARALT, «La angustia secreta del exilio: el testimonio de un morisco de Túnez», Actes de la I Table Ronde du C.I.E.M. sur la Literatura aljamiado-morisque: Hybridisme linguistique et univers discursif, Tunis, 1986, pp. 55-80.

38. L. CARDAILLAC, «El problema morisco y el descuaje del Islam peninsular», en J.B. VILAR (ed.), Murcia, frontera demográfica en el sur de Europa (I y II Jornadas de Inmigración Magrebi, marzo 1993-mayo 1994, Murcia, 1995, p. 14 (pp. 11-20). 


\section{LA GEOGRAFÍA MORISCA DE TÚNEZ}

El colectivo inmigrado se agrupó desde su llegada en los núcleos urbanos ya existentes, sin perjuicio de establecerse también en el ámbito rural inmediato a aquellos. A su vez, en parajes más apartados donde fundaron nuevos asentamientos.

"Grupo tras grupo -anota el recientemente desaparecido historiador y arqueólogo Slimane M. Zbiss (o Sbiss) ${ }^{39}$, ilustre descendiente de una familia morisca levantina apellidada Llopis en la patria de origen-, arribaron estas colonias de españoles para instalarse en diferentes barrios de la ciudad de Túnez (Sidi Bu Said, etc.). Después de haber ocupado todo el espacio disponible en Ras ed-Darb, donde instalaron su morkad o mercado, los llegados posteriormente hicieron lo propio en el arrabal de Bab Souika o barrio de los Andalusíes, llamado así en recuerdo de sus primeros pobladores, los musulmanes españoles llegados en el siglo XIII con Ar-Ramimi. El sector de los huertos extramuros no tardó en ser invadido. Allí surgió otro arrabal netamente español, conocido con el nombre castellano Vega, vocablo arabizado luego en Biga".

Y añade seguidamente: "La expansión prosiguió por las inmediaciones de la ciudad, tanto al N. como al S. Tales son los orígenes de las dos barriadas actuales conocidas como as-Sabhha o Salinas [...]. La distribución de los recién llegados por el país no representó dificultad alguna. Los agricultores moriscos recibieron (de Uțān Dey) diferentes predios abandonados, en los cuales surgieron pueblos de aspecto español. En los alrededores de Túnez colonizaron Ariana, Soukra, los parajes inmediatos a El Bardo, el de Manouba y, no lejos de este punto, el sector conocido hoy como Al-Haraïriya, donde los artesanos de la seda plantaron innumerables moreras".

En efecto, la ciudad de Túnez fue el gran centro morisco del país, y al propio tiempo plataforma de redistribución de inmigrantes por las comarcas próximas. Los inmigrados llegaron a controlar buena parte del artesanado y el comercio de la capital, sectores en los que se operó, más que una reactivación o un renacimiento, un auténtico despegue desde cero, en torno sobre todo a la fabricación de la shashiyah o chéchia, bonete de paño rojo similar al fez pero de formas más redondeadas, por cuya calidad se impuso primero en el país, para inundar a continuación los mercados mediterráneos e islámicos. Fue ésta, sin duda, una de las principales fuentes de trabajo en Túnez por largo tiempo.

Los patronos utilizaban numerosa mano de obra especializada, pero daban también trabajo a domicilio, movilizándose en torno al negocio de la chéchia una impresionante masa laboral insertada en las diferentes fases de la

39. S.M. ZBISs, Presence espagnole à Tunis (s.l.) (s.a.). Texto dictalografiado en Biblioteca Nacional de Madrid, Africa, C. ${ }^{\text {a } 7.029, ~ n}$ n $^{23}$, fs. 7-8 (11 fs.). Publicado posteriormente en M. de EPALZA y R. PETIT, op. cit., pp. 267-270. 
preparación de los productos básicos, fabricación y comercialización: desde el cardado y preparación de la lana y otras fibras textiles utilizadas, consumidas en cantidades impresionantes, a las fases de tejido, tintado, acabado y de colocación del artículo dentro y fuera del país. Tan saneado negocio no dejaría de suscitar competidores, incluso en la Europa cristiana, incluido un curioso proyecto auspiciado por Jovellanos, avanzado el siglo XVIII ${ }^{40}$.

No fue este el único sector productivo de la gran ciudad con neta presencia morisca. Los inmigrados se introdujeron en los diferentes oficios urbanos para revitalizar sus técnicas y, en ocasiones, terminar controlándolos. Así en cuanto se refiere a la fabricación y comercialización de telas y paños, y a la confección de ropas, sector en el que pusieron una impronta inequívoca de calidad, distinción y elegancia, como los deliciosos coiffes comercializados en el Souk el-Kouafi, o las finas sederías de Al-Haraïriya que, hay que decirlo, tenían su mejor clientela en las damas moriscas.

Igualmente cabe decir de otras parcelas artesanales, que iban desde los trabajos de la madera, el cuero y el metal, a la fabricación de perfumes, cerámicas y yeserías decorativas ${ }^{41}$. Y desde la incursión en el campo de la alimentación con el perfeccionamiento de las técnicas del refinado del aceite y las usuales en el sector harinero, a la introducción de novedades gastronómicas y de repostería llamadas a incorporarse a los platos tunecinos habituales. Así el banadij o empanadas, la ojja u olla levantina y catalana, los kigales y las keyeres, y la multiplicidad de platos condimentados con pimentón murciano, tan del gusto de los tunecinos actuales, o los postres donde sabiamente se combinan la harina de trigo, la miel y los frutos secos. El vocabulario castellano, y en ocasiones también el catalán en sus diversas variantes, inundó el mundo de los oficios con vocablos que han llegado hasta hoy: batán, banco, crudar, cardar, affinar, etc. ${ }^{42}$.

Desde Túnez, donde la presencia morisca es recordada en la actualidad con los nombres hispanos de sus barrios -Biga, Bardo (o Pardo), Morkadih (o Mercado)-, numerosas familias colonizaron toda la cornisa septentrional del país entre Bizerta y cabo Bon, semidespoblada, excepto los lugares fuertes de la costa, por haber sido muy castigada en el curso del siglo XVI tanto por las fre-

40. Véase R. RICART, «Espagne et la fabrication des bonnets tunisiens: à propos d'un texto du XVIII ${ }^{\mathrm{e}}$ siècle», Revue Africaine, C, 1956, pp. 423-437; L. VALENSI, «Islam et capitalisme: production et commerce des chéchias en Tunisie et en France aux XVIII ${ }^{\mathrm{e}}$ et $\mathrm{XIX}^{\mathrm{e}}$ siècles», Revue d'Histoire Moderne et Contemporaine, XVII, 1969, pp. 376-400; Id., Le Magreb avant la prise d'Alger (1790-1830), París, 1969; S. FERCHIOU, Tecnique et societé: la fabrication de la chéchia en Tunisie, París, 1971; M. Kraiem, La Tunisie précoloniale, Tunis, 1973, 2 vols.

41. J. RENAULT, «Influence de l'art andalou sur le décor de l'architecture domestique à Tunis», en Mélanges d'Archéologie, d'Epigraphie et d'Histoire offerts à Slimane Mustapha Zbiss, pp. 273-282.

42. S. BOUBAKER, «Activités économiques des morisques et conjoncture dans la Régence de Tunis au XVII ${ }^{e}$. siècle», en V. FANJUL MARLÉ (coord.), op. cit., pp. 129-138; R.Y. BAHRI, «Les morisques en Tunisie un siècle aprés leur arrivée», en V. FANJUL MARLÉ, op. cit., pp. 157-176; M. BEN ACHOUR, «Notes sur les caracteres originaux de la présence morisque dans la ville de Tunis», en S.M. ZBISS, op. cit., pp. 13-22. 
cuentes incursiones y razzias de españoles e italianos, como por las reyertas locales e incursiones de turcos, argelinos y nómadas del sur. La desaparición de la presión extranjera, y habiendo alcanzado el país un aceptable nivel de estabilidad interna en los primeros años del XVII, posibilitó el poblamiento y colonización de aquellos desolados parajes. Bizerta -con su barrio morisco de Hayy al-Andalus, todavía existente-, Ghar el Melh (antiguo Porto Farina), La Goleta y Solimán se convirtieron en centros de asentamiento y redistribución de colonos en todo el frente marítimo del dilatado golfo tunecino.

A este siguió la región de cabo Bon, entonces muy inhóspita, y comarcas interiores como el valle de Medjerda, surgiendo importantes núcleos de población hispana en Tebourba, Zaghuan y Testour, esta última localidad, centro morisco en el Túnez rural y segunda gran concentración de inmigrados después de la capital ${ }^{43}$. Testour, villa morisca por definición, donde los recién llegados no tardarían en controlar la administración municipal y la totalidad de las manifestaciones de la vida ciudadana y profesional, dominada su silueta por el bello alminar de su gran mezquita Zituna o Aceituna, conserva hoy enteramente ese inequívoco aspecto de ciudad española provinciana.

Asentamientos moriscos que merecen mención aparte son los ribāț, institución religioso-militar entre casa de recogimiento y torre de vigilancia y defensa, que llegaron a cubrir la práctica totalidad del litoral tunecino, y norteafricano en general, si bien los hubo también en el interior del país. Manuela Marín refiere que "una noticia podía llegar desde Alejandría a Túnez en un tiempo brevísimo, gracias a las antorchas que se encendían en los numerosos ribāț que jalonaban toda la costa" ${ }^{44}$. Se hallaban habitados por grupos de morabitos, y los del interior hacían funciones de nexos de comunicación entre fortalezas propiamente tales o entre los núcleos de población ${ }^{45}$.

Finalmente es de señalar que los asentamientos moriscos dejaron profunda impronta sobre la arquitectura y manifestaciones artísticas derivadas (la epigrafía en particular), y en el urbanismo tunecino en general ${ }^{46}$. Sus rasgos recuerdan enormemente las manifestaciones arquitectónico-urbanísticas españolas coetá-

43. S.M. ZBISS, «Quelques sites andalous de Tunisie», Awrâq, I, 1978, pp. 55-57; A. SAADAOUI, Testour du XVII . au XIX . siècle. Histoire monumentale d'une ville morisque de Tunisie, París, 1987.

44. M. MARíN, «El ribāṭ de Al-Andalus y el Norte de África», en VV.AA., La Ràpita islámica. Història institucional i altres Estudis Regionals. I Congrés de les Ràpites de l'Estat Espanyol (1989), Sant Carles de la Ràpita, 1993, p. 126 (pp. 121-130).

45. Sobre los ribāț tunecinos véase S.M. ZBISS, «Le Ribāt institution militaro-religieuse des côtes nord-africaines», Comptes Rendus de l'Academia des Inscriptions et Belles Lettres, Tunis, 1954, pp. 143-155. Sobre esta temática (rábitas de Susa, Monastir-Sfax, Sidi Hilāl, etc.) volvería después en numerosos trabajos. Vid. S.M. ZBISs, L'Art musulman en Tunisie, Tunis, 1978. Véase también J. VERNET, «Historia, astronomía y montañismo», Al-Qanțara, II, 1981, pp. 365-381; A. GAFSI [-SlAmA], "Aperçus sur les architectes morisco-andalous en Tunisie», Actes du IV ${ }^{e}, C I E M$, Túnez, 1990, pp. 129-142.

46. A. SAADAOUI, «Urbanisme et architecture des morisques en Tunisie», en V. FANJUL MARLÉ, op. cit., pp. 177-189. 
neas ${ }^{47}$, como sucede igualmente en las restantes manifestaciones culturales, costumbres y vida cotidiana, de que dan fe numerosos testimonios entre los siglos XVII y $X X^{48}$, rasgos inequívocamente hispanos que han llegado hasta hoy.

\section{CONTRIBUCIÓN MORISCO-ANDALUSÍ AL PROCESO DE RENOVACIÓN AGRARIA Y A LA MODERNIZACIÓN DEL PAÍS. SU HUELLA EN LA CULTURA TUNECINA ACTUAL}

Ocupando el sector primario un lugar emergente en la economía de Túnez, y muy especialmente en la etapa de referencia, bien merece atención aparte la incidencia de la inmigración morisca del XVII sobre el agro tunecino y su renovación.

En efecto, la influencia de los moriscos en la revolución agrícola tunecina de los siglos XVII y XVIII, puesta ya de manifiesto por los viajeros europeos coetáneos, es un fenómeno que, aunque objeto reciente de discusiones y sin duda susceptible de matizaciones, responde a una realidad incuestionable. Se trata de una doble contribución, en cuanto a la renovación y progreso de las técnicas agronómicas, y en cuanto a la extensión del área cultivada mediante la bonificación de tierras hasta el momento baldías o sometidas a cultivos inestables o rotativos. Testour sobre todo fue exponente de una colonización colectivista fundada en el cultivo intensivo y en técnicas agronómicas avanzadas ${ }^{49}$.

47. S. FRAYSSINHES, «Aragón y Túnez, un parentesco arquitectónico. Las aportaciones moriscas», en A. Temimi (ed.), Mélanges Louis Cardaillac..., I, pp. 293-302; A. GAFsi-Slama, "Aperçu sur l'ancien palais de Mustafa de Cárdenas à Grombalia», en A. Temimi (ed.), Mélanges Louis Cardaillac..., I, pp. 303-318; Id., "La medersa des moriscos andalous à Tunis», Sharq Al-Andalus, 5, 1988, pp. 109-180; Id., "Chrétiens convertis et moriscos-andalous en Tunisie au XVII ${ }^{\mathrm{e}}$ siécle d'après les documents epigraphiques», en B. BENNASSAR y R. SAUZET (eds.), Chrétiens et musulmans à la Renaissance, París, 1998, pp. 487-507.

48. Testimonios propiamente moriscos unos, en tanto de viajeros europeos otros, comenzando por los españoles. Las fuentes disponibles son inabarcables. Remitimos a estudios más o menos recientes que, además de su interés intrínseco, remiten a la bibliografía disponible. Aparte de nuestras dos monografías ya mencionadas -véanse notas 1 y 2 supra-, entre otros: M. de EPAlZA, «Nouveaux documents sur les Andalous en Tunisie au début du XVIII siécle», Revue d'Histoire Maghrébine, 17-18, 1980, pp. 79-108; Id., «Nuevos documentos sobre descendientes de moriscos en Túnez en el siglo XVIII», Studia Storica et Philologica in Honorem M. Batllori, Roma, 1984, pp. 195-228; K. CHATER, «Le fait andalou dans la Tunisie du XIX siécle», en A. TEMIMI (ed.), Religion, Identité et Sources Documentaires sur les Morisques Andalous. Actes du II Symposium International du C.I.E.M., Tunis, 1984, I, pp. 165-170; A. GAFSI-SLAMA, "Quelques aspects relatifs au Moriscos-Andalous en Tunisie, d'après le peintre Charles Lallemand et l'archéologue S.M. Sbiss», en A. TEMIMI (ed.), Religion..., I, pp. 121-134.

49. S. HopKINS, «Notes sur l'Historie de Testour», Revue d'Histoire Maghrébine, 9, 1977, pp. 294-313; G. MARÇAIS, «Testour et sa grande mosquée. Contribution a l'étude des Andalous en Tunisie», Revue Tunisienne, 1942, pp. 147-169 (reimpreso en Túnez, 1969; 2ª reimpresión en M. de EPALZA y R. PETIT, op. cit., pp. 278-284); A. KASSAB, «L'evolution d'un village 'andalou': Testour», en M. de Epalza y R. PeTIT, op. cit., pp. 359-368. 
A su lado coexistirá otra agricultura extensiva en zonas de nuevo aprovechamiento o ampliación de cultivos, sin olvidar los saladares y parajes pantanosos de reciente desecación. También en las zonas ganadas al monte bajo y en los antiguos campos abandonados cubiertos de malezas, áreas situadas en las inmediaciones de la estéril cornisa marítima ubicada entre los cabos Negro y Bon ${ }^{50}$. Pero aún aquí un riachuelo o un manantial posibilitaba la más floreciente horticultura.

El arrendamiento de tierras por modestos cultivadores, la utilización colectiva de los medios de producción y la pequeña propiedad, rasgos todos ellos dominantes en el agro morisco de Túnez, no impedirían la formación de propiedades medias al invertirse en la tierra los beneficios acumulados, e incluso el surgimiento de verdaderos latifundios y aun de una agricultura casi capitalista en casos excepcionales como el de Mustafa Al-Qardanash, o de Cárdenas, señor de Grombalia, jeque o representante de los andalusíes ante el bey, máximo propietario de esclavos en Túnez, creador de grandes plantaciones de frutales y difusor del olivo - pronto principal riqueza tunecina- por todo el país ${ }^{51}$. "Cárdenas -apunta Epalza ${ }^{52}$ - invirtió el fruto de sus ganancias como mercader en una producción agrícola intensiva, usando por primera vez en el Magreb de la mano de obra masiva de los esclavos, como los españoles en Sudamérica, en vez de emplearlos sólo en trabajos domésticos o de obras públicas, como era habitual hasta entonces".

Igual cabe decir de la influencia de los inmigrados moriscos sobre la renovación y expansión de otras actividades económicas. Comenzando por el comercio tanto interno como internacional, este último no obstante la inseguridad de los mares por causa del corso. Se sabe del mantenimiento de un activo tráfico tunecino con las restantes dependencias del Imperio otomano, tráfico que coexistía con otro más o menos regular con puertos de la Europa cristiana no hispana: Marsella y Liorna, por ejemplo ${ }^{53}$.

50. Vid. F. Collot, «La côte orientale du Cap Bon: Habitations et habitat», Ibla, 70, 1954, pp. 415435; Id., «La côte orientale du Cap Bon: Peuplement et population», Ibla, 71, 1955, pp. 323-338; H.H. ABDUlWAHAR, «Coup d'oeil general sur les apports ethniques étrangers en Tunisie», en M. de Epalza y R. PETIT, op. cit., pp. 9-15; M.H. El-HILA, «L'élement andalou en Tunisie, selon le ‘Hulal Al-sandusiya' d'Al-Sarrag Al-Andalusi», en M. de EPALZA y R. PETTT, op. cit., pp. 264-266; J. RENAULT, "Aspects de l'element andalous dans le palais et demeures de Tunis», en M. de EPALZA y R. PETIT, op. cit., pp. 291-303; H. SETHOM, «L'apport andalou à la civilisation rurale de la presqu'ile du Cap Bon», en M. de Epalza y R. Petit, op. cit., pp. 369-373; M. ElaOuAnI, «A la recherche des influences andalouses dans les champagnes tunisiennes: essai de mise au point», M. de EPALZA y R. PETIT, op. cit., pp. 374-377. Precisiones y actualización de la temática de referencia en S.M. ZBISS, «Apports des Morisques andalous en matière d'agriculture en Tunisie», Actes du II Symposium International du C.I.E.M., II, pp. 201-212; A. GAFSI[-SLAMA], «Crues, inondations et contròle de l'eau dans quelques villages morisco-andalous de Tunisie», en A. GIL OLCINA y A. MorALES GIL (eds.), Avenidas fluviales e inundaciones en la cuenca del Mediterráneo, Alicante, 1989, pp. 403-414.

51. J.D. Latham, «Mustafá de Cárdenas», Les Africains, VII, 1977, pp. 199-299.

52. M. de EPALZA, «Trabajos actuales...», p. 431.

53. S. BOUBAKER, La Régence de Tunis au XVII . siécle: ses relations commerciales avec les ports de l'Europe méditérranée: Marseille et Livourne, Zaghouan, 1987. 
La presencia morisca en Túnez, tan intensa y continuada, ha dejado huella profunda en la onomástica tunecina. Permanecen apellidos como Blanco, Nigru, Bentor (Pinto), Pérez, Rubio, García, Gundi (Conde), Grandel, Méndez, Sancho, Herrera, Merkiku, Mirichku (Morisco), Mador (Amador), Zbiss (Llopis), Marco, Kabadu (Quevedo), Manacho, Bonatiro e incluso Christo, en tanto otros delatan en los suyos procedencia de una región o ciudad determinada. Así los Teruel, Uichka (Huesca), Soria, Catlani (Catalán), Balma (Palma), Alikanti (de Alicante), Karabaka (Caravaca), Kortobi (de Córdoba), Ichbili (de Sevilla), Malqi (de Málaga), Hendili (de Hendín, Granada), o al-Munakkabi (de Almuñécar). La serie no se agota aquí, aparte de que no pocos moriscos cambiaron sus apellidos originarios por otros árabes y turcos, en ocasiones traducción literal de aquéllos, como la familia Kchuk, originariamente Ríos ${ }^{54}$.

Por último, la contribución morisca al mundo de la cultura tunecina es difícilmente exagerable. Los hombres de letras moriscos insuflaron nueva vitalidad a un panorama intelectual limitado por excesivas ataduras medievales. Pero tampoco descuidaron las necesidades de su propia comunidad castellanoparlante -existían también grupos más reducidos catalanoparlantes, originarios preferentemente del reino de Valencia-, alentando la fidelidad al patrimonio cultural ancestral, haciendo a la lengua vernácula objeto de cultivo literario como Juan Pérez de Alcalá, Abd el Krim Ben Ali Pérez, Ahmad Bejarano, Muhammad Rabadán o el anónimo "morisco de Túnez admirador de Lope", llegado de Madrid y autor de un libro estudiado por J. Oliver Asín ${ }^{55}$, donde da a conocer y comenta con fines moralizadores el argumento de varias comedias de Lope de Vega.

La mayor parte de estas obras responden a una intencionalidad religiosa, y más exactamente catequética. Al deseo de vigorizar a los hermanos del exilio en la fe de los antepasados, en ocasiones entibiada o desvirtuada por un conocimiento imperfecto y por la incorporación de contenidos espúreos tomados del cristianismo. A tan piadoso fin, sin perjuicio de fomentar en ocasiones las letras puras, se encaminará la munificencia de hombres de negocios como Muhammad Rubio, opulento comerciante aragonés llegado a Villafelice, mecenas en la Regencia tunecina de Bejarano y otros correligionarios compañeros de exilio, y que "viajaba entre Túnez y la capital del Imperio otomano y compraba libros en castellano" ${ }^{\prime 56}$. Iguales preocupaciones intelectuales tuvieron otros compatricios, oriundos o no de Aragón, pero residentes en Túnez o relacionados con este país, como Muhammad de Vera, Mustafa de Aranda, Juan Alonso Aragonés o los Castellani-o Castellano-, en ocasiones también escritores de mérito ${ }^{57}$.

54. Vid. N. ZBISS, «L'onomastique espagnole en Tunisie», Sharq Al-Andalus, 7, 1990, pp. 215-220.

55. J. Oliver Asín, op. cit.

56. M. de EPALZA, «El escritor Ibrahim Taybili...», p. 8.

57. M. de EPAlZA, «Arabismos en el manuscrito castellano del morisco tunecino Ahmad al-Hanafi», Homenaje a Álvaro Galmés de Fuentes, Madrid-Oviedo, vol. II, 1985, pp. 515-527. El manuscrito 
La música conoció una renovación todavía más notable, cuyos efectos perduran hoy: los aires melancólicos del maluf, que evocan el país perdido y cantan las bellezas del de recepción, estilo hoy generalizado por todo el país, al que los musicólogos señalan inequívocas raíces hispánicas. Igual parentesco cabe señalar al cante fundu, género particular de canto introducido por los moriscos, conectado a la música actual andaluza y a la popular de Cataluña.

Pero sobre todo la impronta morisca es particularmente visible hoy en el urbanismo -pueblos andaluces como Sidi bu Said, Testour y Zaghuan-, en la definitiva conformación en el siglo XVII de la casa tunecina tradicional, y en la arquitectura monumental, especialmente en los edificios religiosos, continuación en esto del gran arquitecto hispano Ibn Ghalib al-Andalusi, que dejó huella indeleble en varios de los mejores monumentos históricos de Túnez, desde la mezquita mayor de la ciudad y la fastuosa mansión porticada que mira al mercado de El Fakka, a diferentes mezquitas menores, mausoleos y palacios ${ }^{58}$

En pleno siglo XVIII la presencia morisca en el país resultaba todavía perceptible a simple vista, incluso para los observadores foráneos menos avisados. Raro es el viajero europeo que no se refiere a ella, y algunos, como los españoles, con especial interés. Así el trinitario toledano fray Francisco Ximénez, residente un tiempo en la Regencia, quien hacia 1720 enaltecerá la aportación de los moriscos hispanos al desarrollo demográfico, económico y cultural de Túnez. "Los Moriscos expelidos de España por Felipe tercero -refiere ${ }^{59}$ - ennoblecieron este Reyno con más de veinte poblaciones que fabricaron; las mejores Textor, Soliman, Taborda y Matar, y aumentaron otras ciudades y lugares que ya subsistían".

Tal realidad no escaparía tampoco a quienes conocían el país de forma bastante más superficial que Ximénez. Por ejemplo el también religioso espa-

en cuestión fue dado a conocer, en su día, por G. LEVI DeLLA VIDA, «Manoscritti arabi di origine spagnola nella Biblioteca Vaticana», Colectanea Vaticana in Honorem Anselmi M. Card. Albareda, Roma, 1962, vol. II, pp. 181-184. Sobre manifestaciones literarias en castellano de los moriscos en Túnez y proyección cultural morisca en ese país es fundamental la consulta de J. PENELLA, «Littératura morisque en espagnol à Tunis», en M. de Epalza y R. PETIT, op. cit., pp. 187-198. Sobre igual temática interesan, entre otros, los estudios de M. de Epalza, H. Pieri, D. Barhimi, L.P. Harvey, C. Sarnelli, M.H. El-Hila, A. Daoulatli, M. Annabi y P. Teyssier. A su vez, recientes investigadores sobre la lengua, literatura y cultura de los moriscos en Túnez son, entre otras, las de A. Alwaragli, H. Bouzineb, A.A. Abdurrahim, R. Limam, B. Ben Mami, M. Boulajfen y M. Fekih, todas ellas aparecidas en lengua árabe y recogidas, junto a otras colaboraciones sobre temática morisca no referida a Túnez, en el vol. I de Actes du II Symposium International du C.I.E.M., Tunis, 1984. Finalmente, sobre el tema de referencia puede verse también amplio repertorio bibliográfico en L.F. BERNABÉ PONS, El cántico islámico..., pp. 269-274.

58. Sobre la influencia morisca en las artes y costumbres tunecinas cabe destacar, entre otras, aparte de las ya mencionadas, las aportaciones de S.M. Zbiss, G. Marçais, A. Daoulatli, M. Annabi, S. Ferchiou, P. Teyssier, F. Skhiri, C. Sugier, A. Kassab, M. Turki y A. Gafsi-Slama.

59. Fr. F. XIMÉNEZ, Colonia trinitaria de Túnez, edición de I. Bauer, Tetuán, 1934, p. 17 (Selección del ms. original conservado en la Academia de la Historia, Madrid). No faltan otros testimonios coetáneos, sobre todo españoles e italianos. Vid. S. BONO, «Tunisi ai tempi di Yusuf Dey. La relatione di Don Paolino Bianchi (1625-1628)», en M.H. FANTAR y S. KHADDAR-ZANGAR, op. cit.; S.M. ZBISS, op. cit., pp. 63-82. 
ñol Melchor García Navarro, de la Orden de la Merced, en rápida visita en 1725 con ocasión de una misión para la redención de cautivos. García describe así a los tunecinos y sus costumbres ${ }^{60}$ : "Los pactos se obseruan en Túnez con segura puntualidad, y los estilos tan inviolablemente como los pactos; porque son hombres joviales, cortesanos; y en lo político, se goviernan por la luz de la razón". Y concluye: "Précianse de españoles como descendientes muchos de los expulsos de España; y lo son en el trato real y fiel". Talante este y costumbres que, a su juicio, contrastaba con la adustez de los argelinos.

Y en otro lugar referirá nuestro informante ${ }^{61}$ que apenas se supo que había llegado una misión de religiosos españoles para redimir a los cautivos oriundos de España, recibieron numerosas visitas de moros principales, "que son en Túnez muy joviales y cortesanos, preciados de españoles como descendientes de ellos; y así nos daba gusto oírles preguntar por apellidos de España y por determinados lugares [de donde decían] auer venido sus abuelos, que nombraban con los mismos apellidos".

Todo ello conllevaba un cierto sentimiento de superioridad respecto a sus correligionarios del país de recepción, que en ocasiones no dudaba en manifestar directa o indirectamente so pretexto de salvaguardar la propia identidad, incluso en el plano religioso -ritos propios ${ }^{62}$ - o en el educativo ${ }^{63}$. "Funda [el morisco] nuevos núcleos de población y vive en comunidades semiautónomas -referirá un observador actual ${ }^{64}-$, rechazando los matrimonios mixtos con los tunecinos de origen. Todavía hoy cree distinguirse somáticamente de su compatriota de ascendencia distinta y conserva orgullosamente su apellido hispánico". El autor de referencia trae a colación, por ejemplo, el caso del poeta tunecino Abd al-Razzaq Karabaca, fallecido en 1945, que con toda naturalidad se declaraba oriundo de Caravaca y perteneciente a una conocida familia islámica de artesanos de esa localidad murciana en el momento de la expulsión.

Por más que la asimilación de los moriscos a la larga tenía que imponerse, el grupo inmigrado retuvo su personalidad propia por largo tiempo, hasta bien entrado el siglo XVIII ${ }^{65}$, y en algunos aspectos diferentes rasgos bien dis-

60. M. García NaVArRo, Redenciones de cautivos en África (1723-1725), edición, prólogo y notas de M. Vázquez Pájaro, O. de M., Madrid, 1946, pp. 242-243.

61. Ibídem, p. 284.

62. Vid., por ejemplo, M. TURKI, «Le mariage morisque en Tunisie tel qu'il est encore practiqué actuellement», en A. TEMIMI (ed.), Actes du VII ${ }^{e}$. Symposium International d'Études Morisques: Famille Morisque, Zaghouan, 1997, pp. 305-309.

63. A. GAFSI-SLAMA, «Aperçu su la population infantile masculine dans quelques villages moriscoandalous de Tunisie au XIX ${ }^{\mathrm{e}}$. siécle», en A. TEmIMI (ed.), Actes du VII Symposium..., pp. 101-115.

64. J. SAMSÓ, op. cit., p. 29.

65. M. de EpalzA, «Moriscos y andalusíes en Túnez durante el siglo XVIII», Al-Andalus, XXXIV, 1969, pp. 247-329 (artículo traducido al francés en M. de EPAlZA y R. PETIT, op. cit., pp. 150-186); M. de EPAlZA, «Nouveaux documents sur les andalous en Tunisie au debut de XVIII" . siècle», Revue d'Histoire Maghrébine, 17-18, 1980, pp. 79-108; M. de EPALZA, «Nuevos documentos sobre descendientes de moriscos...», pp. 195-228. 
cernibles de su entidad cultural han sobrevivido, incorporados a la civilización tunecina actual ${ }^{66}$.

\section{RESUMEN}

Análisis global de la emigración morisca en Túnez tras la expulsión de España a comienzos del siglo XVII. Caracterización geográfica de los moriscos, política otomana para con ellos, con la intervención de las autoridades de Túnez, instalación en el país y descripción de su universo religioso y cultural, multiforme tanto en España como en Túnez. Recorrido interdisciplinar e historiográfico por las influencias que los moriscos dejaron en la sociedad tunecina, ya testimoniadas desde el siglo XVIII.

Palabras clave: moriscos, expulsión, Túnez, asimilación, legado, historiografía.

\section{ABSTRACT}

Global analysis of the Morisco migration in Tunisia after the expulsion from Spain at the beginning of the $17^{\text {th }}$ Century. Geographic characterization of moriscos, Ottoman policy towards them, with the intervention of the Tunisian authorities; Morisco settlement in the country and description of their religious and cultural universe, and its multiple expressions both in Spain and Tunisia. Interdisciplinary and historiographic revision of the influence of Moriscos in Tunisian society, already evident since the $18^{\text {th }}$ Century. graphy.

Key words: moriscos, expulsion, Tunisia, assimilation, legacy, historio-

66. Sobre el particular, aparte de los trabajos contenidos en el libro varias veces citado de M. de Epalza y R. Petit, otras varias monografías y estudios de diferentes autores ya mencionados, que remiten a la amplia bibliografía disponible, incluidas aportaciones tan específicas como la de A. GAFSI[-SLAMA], «Estudio socioeconómico de un pueblo andalusí tunecino: Kal'at alAndalus de 1847 a 1881», Almenara, 9, 1976, pp. 83-93, y de M. BEN ALI, «Un pueblo andalusí en el siglo XIX: Soliman», Miscelánea de Estudios Árabes y Hebraicos, 25, fasc. 1, 1978, pp. 8393, resúmenes de sendas memorias de Maitrise, y punto de arranque de dos fructíferas y ejemplarizantes andaduras investigadoras, que evidencian además el interés por el colectivo morisco-andalusí en la historiografía tunecina actual. 